in vivo $34: 2675-2685(2020)$

doi:10.21873/invivo.12087

\title{
Long-term Results of Surgery for Colorectal Liver Metastases in Terms of Primary Tumour Location and Clinical Risk Factors
}

\author{
VLADISLAV TRESKA, MARTIN SKALA, KRISTYNA PROCHAZKOVA, ANETA SVEJDOVA, \\ TEREZA PETRAKOVA, JAKUB SEBEK, IVAN RIHA, JACHYM ROSENDORF, \\ ROBERT POLAK, TOMAS SKALICKY and VACLAV LISKA
}

Department of Surgery, University Hospital, School of Medicine in Pilsen, Pilsen, Czech Republic

\begin{abstract}
Background/Aim: The aim of the study was to evaluate the influence of primary tumour location and clinical risk factors for long-term results of surgery for colorectal liver metastases (CLMs). Patients and Methods: Overall survival (OS) and recurrence-free survival (RFS) were evaluated in 636 patients. Patients were divided by tumour location (right-/left-sided colorectal cancer: $R C R C / L C R C$; rectal cancer), and age, gender, number and size of CLMs, type of liver surgery and interval from primary operation were evaluated. Results: One-, 3- and 5-year OS and RFS were independent of primary tumour location $(p<0.59)$. CLM diameter was negatively associated with OS for the whole cohort $(p<0.002)$, and RCRC $(p<0.03)$ and LCRC $(p<0.04)$ groups, as well as for RFS of those with LCRC $(p<0.04)$. CLM number was negatively associated with RFS for the whole cohort $(p<0.0001), \operatorname{RCRC}(p<0.02)$, LCRC $(p<0.0001)$ and RC $(p<0.02)$. Radiofrequency ablation and combined procedures led to worse OS for the whole cohort $(p<0.03)$, and to worse RFS for the whole cohort $(p<0.0003)$ and for those with LCRC $(p<0.03)$. A shorter interval between primary colorectal cancer surgery and CLMs procedure was risky for poor OS and RFS of patients with CLMs from RCRC $(p<0.05), L C R C(p<0.05)$ and $R C(p<0.02)$. Conclusion: Primary tumour location together with clinical risk factors are important for longterm results of surgery CLMs.
\end{abstract}

This article is freely accessible online.

Correspondence to: Vladislav Treska, Professor of Surgery, MD, Ph.D., Department of Surgery, University Hospital, Alej Svobody 80, 30460 Pilsen, Czech Republic. Tel: +42 0377104270, e-mail: treska@fnplzen.cz

Key Words: Colorectal carcinoma location, liver metastases, risk factors, liver surgery, long, term results.
Globally, colorectal cancer (CRC) is the third most common carcinoma $(1,2)$. Colorectal liver metastases (CLMs) appear in more than $50 \%$ of patients at various time intervals from the diagnosis of CRC and are the main cause of death. However, thanks to the constantly increasing quality of multimodal procedures in the treatment of CLMs, where liver resections are the only radical treatment, there has been a steady improvement in the long-term results, with 5-year overall survival (OS) currently reaching 45-60\%. However, $70 \%$ of patients experience a recurrence of CLMs at different time intervals, most often in the first 2 years after a liver operation (3-6).

In addition to many known risk factors influencing longterm survival of patients after surgical treatment of CLMs, recent studies report the location of the primary tumour being a significant prognostic factor for these patients $(7,8)$. Tumour biology is different for right- (RCRC) and left-sided CRC (LCRC), with different response to chemotherapy and target therapy. According to many contemporary metaanalyses, primary tumour sidedness has a decisive impact on OS and recurrence-free survival (RFS) for patients following liver resection for CLMs $(9,10)$. For resection of CLMs in the case of RCRC, OS is worse compared with those with LCRC but RFS is better. Various studies evaluated the longterm results of liver resection regarding tumour sidedness from various viewpoints, primarily the biological activity of primary CRC (11-13). Although most report significantly worse results for long-term $\mathrm{OS}$ in the case of surgical treatment of CLM from RCRC (14-16), the results for RFS are inconsistent. Neither is the definition of tumour sidedness consistent in many studies, and in some publications rectal cancer (RC) is included in LCRC, whereas others do not mention it at all due to the different oncological approaches.

The aim of our study was to evaluate the influence of primary tumour location in combination with the factors of age and gender of patient, size and number of CLMs, type of liver operation and the internal from resection of primary 
in vivo $34: 2675-2685(2020)$

Table I. Demographic data, clinical characteristics, and type of operation(s) for study patients.

\begin{tabular}{|c|c|c|c|c|c|c|}
\hline Characteristic & & Total $(n=636)$ & $\operatorname{RCRC}(\mathrm{n}=128)$ & LCRC $(n=334)$ & $\mathrm{RC}(\mathrm{n}=174)$ & $p$-Value \\
\hline Age, years & Mean \pm SD & $63.8 \pm 9.3$ & $64.4 \pm 9.1$ & $63.9 \pm 9.8$ & $62.7 \pm 8.3$ & 0.09 \\
\hline \multirow[t]{2}{*}{ Gender, n (\%) } & Male & $418(65.7)$ & $78(18.7)$ & $207(49.5)$ & $133(31.8)$ & 0.002 \\
\hline & Female & $218(37.3)$ & $127(57.3)$ & $50(22.9)$ & $41(18.8)$ & \\
\hline \multirow[t]{2}{*}{ CLMs, mean $\pm \mathrm{SD}$} & Number & $2.5 \pm 1.9$ & $1.5 \pm 2.3$ & $2.6 \pm 2.2$ & $1.6 \pm 2.7$ & 0.45 \\
\hline & Diameter & $4.0 \pm 2.4$ & $4.0 \pm 2.2$ & $4.0 \pm 2.3$ & $4.0 \pm 2.7$ & 0.84 \\
\hline Interval between operations, years & Mean \pm SD & $1.4 \pm 1.7$ & $1.4 \pm 2.1$ & $1.5 \pm 1.8$ & $1.7 \pm 2.9$ & 0.64 \\
\hline \multirow[t]{2}{*}{ Resection } & Large & 173 & 38 & 93 & 42 & 0.49 \\
\hline & Small & 276 & 64 & 133 & 79 & \\
\hline \multirow[t]{2}{*}{ Therapy } & RFA & 124 & 19 & 70 & 35 & \\
\hline & Combined & 63 & 13 & 32 & 18 & \\
\hline
\end{tabular}

CLMs: Colorectal liver metastases; LCRC: left-sided colorectal cancer; RC: rectum cancer; RFA: radiofrequency ablation; RCRC: right-sided colorectal cancer. Bold values indicate statistical significance.

tumour to liver operation on the OS and RFS of patients with CLMs in order to add to the current literary findings from another point of view.

\section{Patients and Methods}

We analyzed data from 650 patients who had undergone operations for CLMs at a large tertiary hepatobiliary unit in 2002-2018. We excluded 14 due to the incompleteness of the required monitoring factors. For patients for whom we performed repeated liver operations due to CLM recurrence, in regard to the long-term results, we always considered the time-point of the first liver surgery. A multidisciplinary team decided on the indication for surgical treatment. The primary choice of operation was radical $\mathrm{R} 0$ resection with healthy liver tissue border $>1 \mathrm{~mm}$. Over the years of the study, small liver tissue-sparing resections came to predominate over large liver resections. Radiofrequency ablation (RFA) was performed in patients for whom a liver resection was contraindicated for various reasons (overall health patient status, location of CLMs, volume and function of liver parenchyma) providing there were no more than five metastases and their diameter was $<5 \mathrm{~cm}$. For some patients, a combination of resection with RFA was used with the aim of saving liver tissue.

Neoadjuvant oncological treatment was indicated for borderline resectable or primarily non-resectable CLMs. The response to preoperative oncological treatment was evaluated after 4-6 cycles using computed tomography. When there was a treatment response, patients were indicated for liver resection. Adjuvant oncological treatment was indicated for individual patients by an oncologist. All patients underwent regular follow-up examinations after liver resection or RFA.

We obtained written informed consent from all patients who participated in this study (approval no.: 363/2018).

Table I shows the characteristics of the whole cohort and of the subgroups. The primary location of tumour was right-sided in 128 $(20.1 \%)$, left-sided in $334(52.5 \%)$ and rectal in $174(27.4 \%)$. We considered all primary tumours located from proximal to the splenic flexure to be RCRC, those located distal to the splenic flexure and the upper rectum to be LCRC, and tumours located in the middle and lower rectum to be RC.

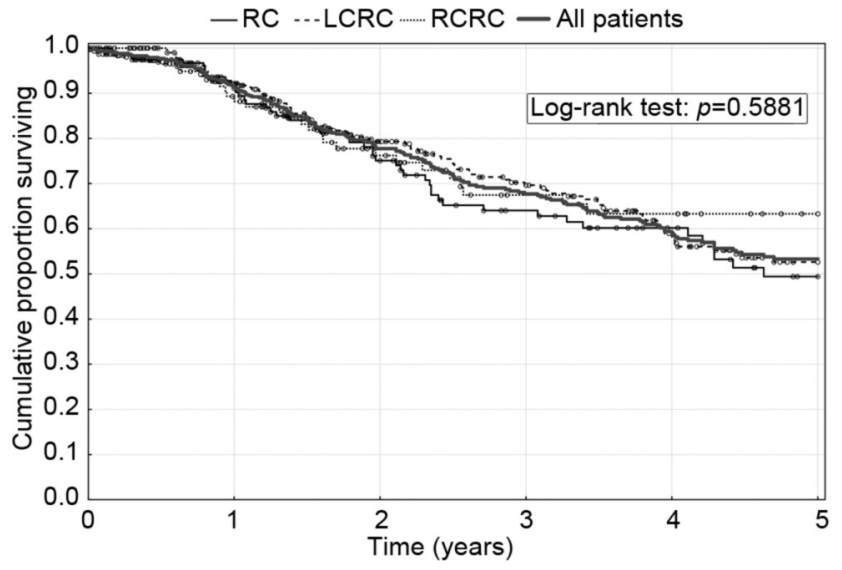

Figure 1. Overall survival of the entire patient cohort and according to disease. LCRC: Left-sided colorectal cancer; RC: rectal cancer; RCRC: right-sided colorectal cancer.

In the whole patient cohort, there were $418(65.7 \%)$ men and 218 $(37.3 \%)$ women $(p<0.002)$. The number of men in the RCRC, LCRC and RC groups was 78, 207 and 133, respectively. The average age of patients with CLMs was $63.8 \pm 9.3$, with a median of 63.7 years. The average age did not differ significantly between groups $(p<0.09)$. The median number of CLMs in the cohort was 3.4, and for RCRC, LCRC and RC tumours it was 2.3; 3.1 and 2.5, respectively; the average number of CLMs did not differ significantly $(p<0.45)$. The average size of CLMs for the whole patient cohort was $4.0 \pm 2.4 \mathrm{~cm}$, and size did not differ significantly between groups $(p<0.84)$. The average interval between surgery for the primary tumour and CLMs was $1.4 \pm 1.7$ years and did not differ significantly between groups $(p<0.64)$. For 173 patients, we performed large liver resection ( $\geq 3$ liver segments), for 276 small liver resection ( $<3$ segments) and for 124 RFA. Combined procedures were performed in 63 patients.

The statistical analysis was performed using SAS software (SAS Institute Inc., Cary, NC, USA). Basic statistical data, such as the average, standard deviation, variance, median, interquartile range, 

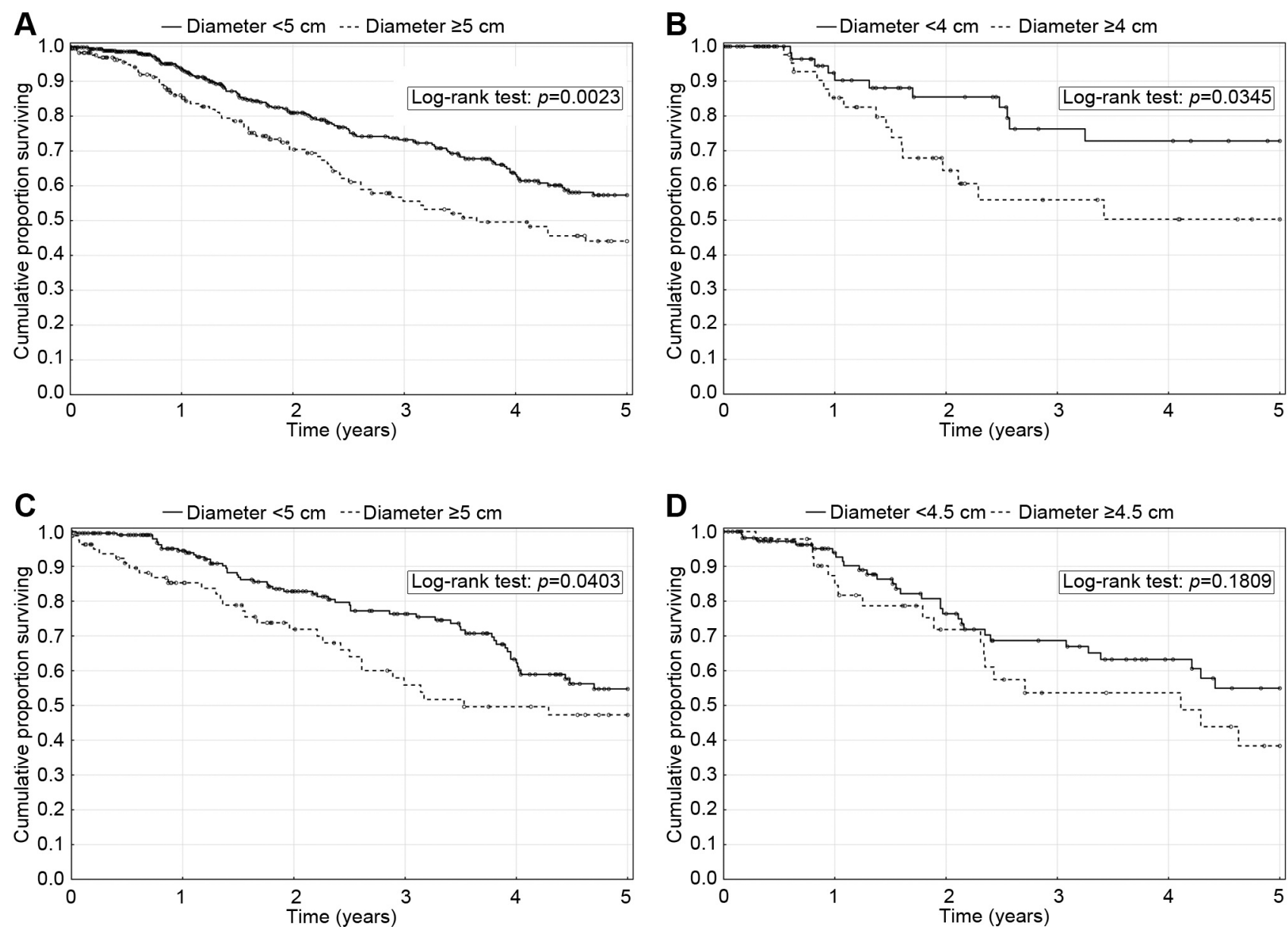

Figure 2. Overall survival according to the diameter of colorectal cancer liver metastases for the whole patient cohort (A), for patients with rightsided $(R C R C)(B)$ and left-sided $(L C R C)(C)$ colorectal cancer, and those with rectal cancer $(R C)(D)$.

minimum and maximum, were calculated for the measured parameters for the whole group and in the individual subgroups. The difference in continuous variables between the examined groups was tested using Kruskal-Wallis test. OS and RFS were calculated from the date of the first liver operation using KaplanMeier survival curves. The influence of the individual factors was tested using the log-rank test, Gehan-Wilcoxon test and Cox regression model. The statistically strongest cut-off of the individual factors met the condition of highest attained score of the Cox regression model. Statistical significance was designated at the threshold alpha of $5 \%$.

\section{Results}

One-, 3- and 5-year OS for the whole patient cohort following surgery for CLMs was $91.3 \%, 61.7 \%$ and $53.3 \%$, respectively; for patients with RCRC, it was $88.2 \%, 67.5 \%$ and $63.3 \%$, respectively; for those with LCRC $92.2 \%, 69.7 \%$ and $52.6 \%$, respectively, and for those with RC $91.1 \%$, $64.1 \%$ and $49.4 \%$, respectively $(p<0.59$, Figure 1$)$.
Regarding the impact of the number of CLMs on OS, we did not find a statistically significant difference $(p<0.35)$. The statistically strongest, yet statistically insignificant, cut-off for number of CLMs was four for the whole patient cohort [hazard ratio $(\mathrm{HR})=1.2,95 \%$ confidence intervaI $(\mathrm{CI})=0.8-1.9, p<0.3]$ and for $\mathrm{RCRC}(\mathrm{HR}=1.5,95 \% \mathrm{CI}=0.5-5.1, p<0.5)$, whilst it was two for both LCRC (HR=0.7, 95\% CI=0.5-1.2, $p<0.2)$ and $\mathrm{RC}$ $(\mathrm{HR}=1.6,95 \% \mathrm{CI}=0.9-2.9, p<0.08)$. Considering the size of CLMs, the statistically strongest diameter of CLMs was $5 \mathrm{~cm}$ for the whole patient cohort $(\mathrm{HR}=1.6,95 \% \mathrm{CI}=1.2-2.2$, $p<0.002)$, for $\mathrm{RCRC}(\mathrm{HR}=2.2,95 \% \mathrm{CI}=0.5-1.2, p<0.03)$ and for LCRC $(\mathrm{HR}=1.6,95 \% \mathrm{CI}=1.0-4.9, p<0.04)$, whilst it was cut-off $4.5 \mathrm{~cm}$ for $\mathrm{RC}$, without statistical significance $(\mathrm{HR}=1.5$, 95\% CI=0.8-2.7, $p<0.2$ ) (Figure 2).

The type of operation was significant for the length of survival for the whole patient cohort $(p<0.03)$, where small liver resections led to the best and RFA to the worst results (Figure 3). The type of operation was not decisive for OS of patients with RCRC $(p<0.7)$, LCRC $(p<0.1)$ and RC $(p<0.4)$. 

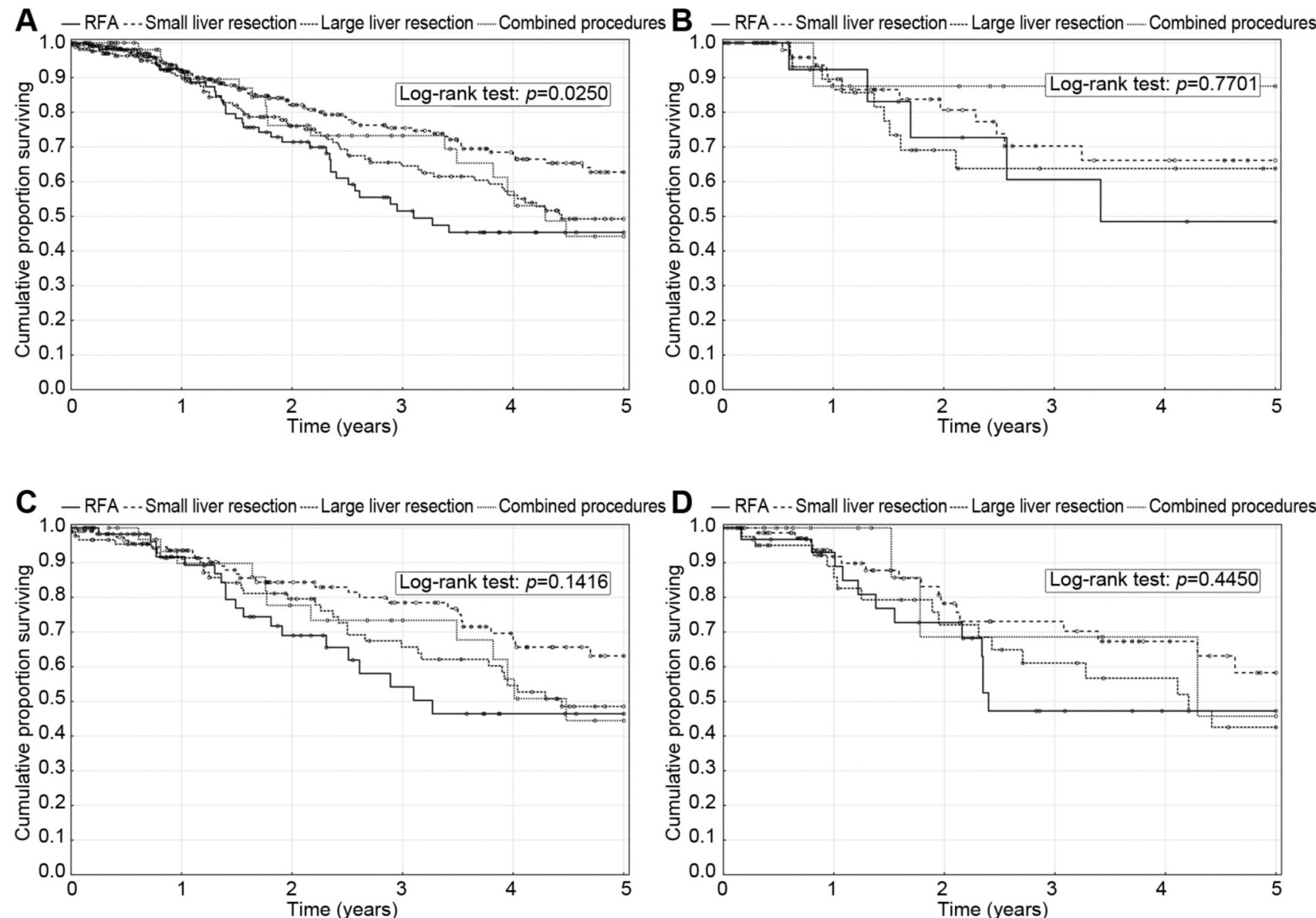

Figure 3. Overall survival according to the type of surgery for the whole patient cohort (A), for patients with right-sided (RCRC) (B) and left-sided $(L C R C)(C)$ colorectal cancer, and those with rectal cancer $(R C)(D)$. RFA: Radiofrequency ablation.

The interval between primary operation and liver procedure was not decisive for the whole patient group $(p<0.2)$, nor for those with RCRC and RC ( $p<0.08$ and 0.54 respectively). For patients with LCRC, an interval from primary surgery to liver procedure shorter than 6 months was significantly predictive of poorer OS ( $\mathrm{HR}=1.6,95 \% \mathrm{CI}=1-2.7, p<0.05)$ (Figure 4).

One-, 3- and 5-year RFS for the whole patient cohort was $58.8 \%, 16.9 \%$ and $11.8 \%$, respectively; for patients with RCRC $55.9 \%, 30.8 \%$ and $25.2 \%$, respectively; for those with LCRC 63.2, 22.7 and 15.5\% and for RC 51.0, 21.2, 14.3\% respectively $(p<0.2$; Figure 5$)$. The statistically strongest cutoff RFS was five CLMs for the whole patient cohort $(\mathrm{HR}=2.1,95 \% \mathrm{CI}=1.5-2.7, p<0.0001)$, for RCRC $(\mathrm{HR}=2.3$, $95 \% \mathrm{CI}=1.1-4.9, p<0.02)$, and $\mathrm{RC}(\mathrm{HR}=2.1,95 \% \mathrm{CI}=1.3-$ $3.5, p<0.002)$, whilst for LCRC the cut-off was four $(\mathrm{HR}=1.9,95 \% \mathrm{CI}=1.4-2.6, p<0.0001)$ (Figure 6). Regarding the size of CLMs, the statistically strongest diameter of was $2.5 \mathrm{~cm}$ for the whole patient cohort $(\mathrm{HR}=1.3,95 \% \mathrm{CI}=0.9$ $1.6, p<0.06)$ and for those with LCRC $(\mathrm{HR}=1.5,95 \%$
$\mathrm{CI}=1.0-2.2, p<0.04)$, whilst the cut-off was $3.5 \mathrm{~cm}$ for $\mathrm{RCRC}(\mathrm{HR}=1.5,95 \% \mathrm{CI}=0.9-2.3, p<0.09)$ and $\mathrm{RC}(\mathrm{HR}=0.9$, 95\% CI=0.6-1.3, $p<0.6$ ) (Figure 7).

RFS in relation to the type of operation differed significantly considering the whole patient cohort $(p<0.0003)$ and those with LCRC $(p<0.03)$, with worse results of RFA and combined operations. The type of surgery was not decisive for RFS for patients with RCRC $(p<0.63)$ and RC $(p<0.07)$ (Figure 8). The interval between primary operation and liver surgery was not decisive for the whole patient cohort $(p<0.17)$ and those with $\mathrm{RC}(p<0.40)$, but for patients with RCRC and with LCRC, an interval of less than 18 months $(\mathrm{HR}=2.5,95 \% \mathrm{CI}=0.2-1.0$, $p<0.05)$, and 6 months $(\mathrm{HR}=1.5,95 \% \mathrm{CI}=1.1-2.0, p<0.02)$, respectively, led to poorer RFS (Figure 9).

\section{Discussion}

The embryonic development of the colon differs in regard to location. Whereas the right colon develops from the 

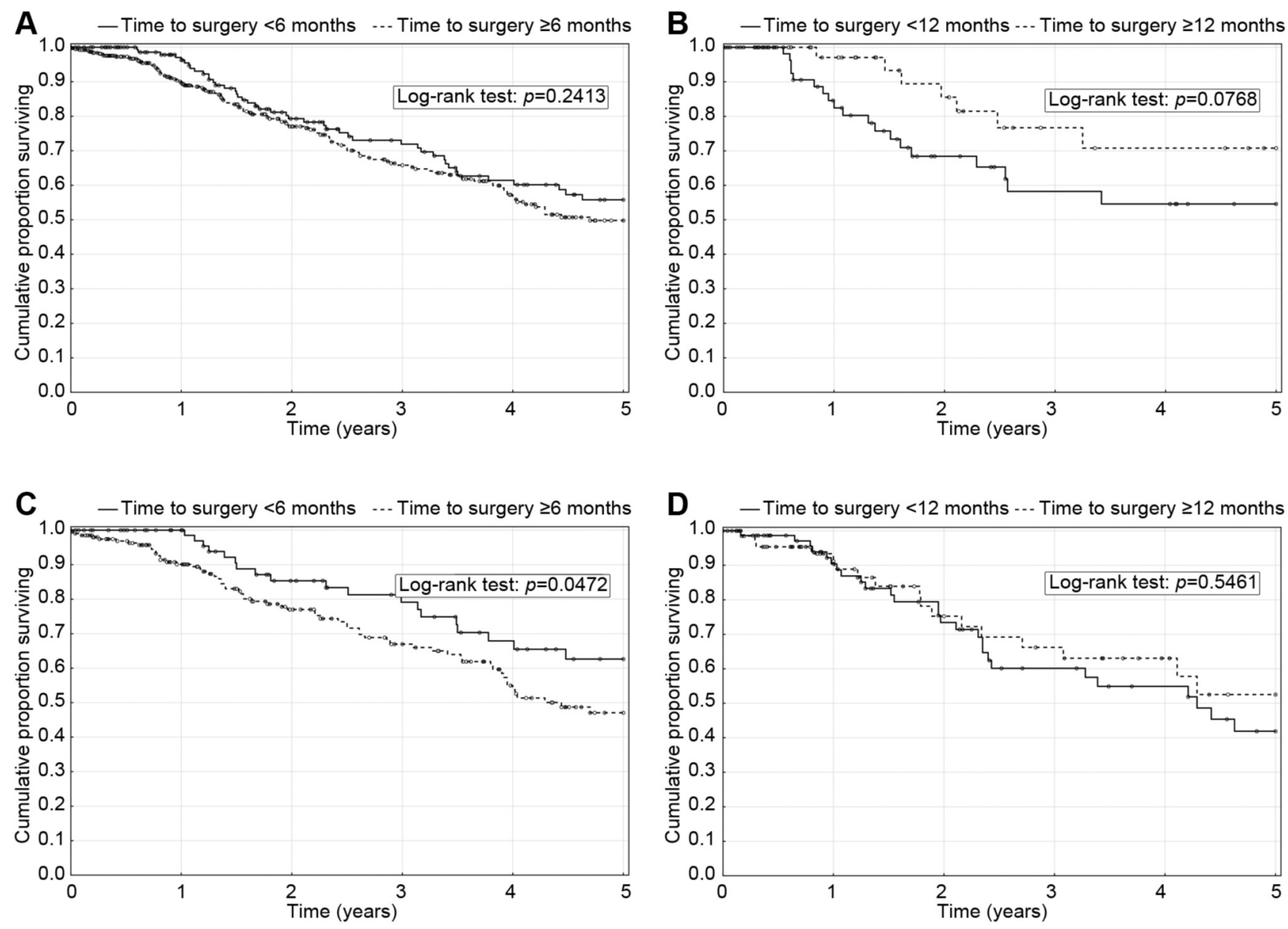

Figure 4. Overall survival according to the time to surgery of colorectal cancer liver metastases for the whole patient cohort (A), for patients with right-sided $(R C R C)(B)$ and left-sided $(L C R C)(C)$ colorectal cancer, and those with rectal cancer $(R C)(D)$.

midgut, the left colon and rectum develop from the hindgut. These parts of the colon then differ in mucosal immunology and in gut microbiota. A higher density of eosinophilic leukocytes and intraepithelial T-cells has been shown in the proximal colon $(17,18)$. Tumours from both parts of the colon are further distinguished by certain clinicopathological properties that can influence the long-term survival of patients, both after resection of primary tumour and after operations for CLMs $(19,20)$. RCRC are more common in the older population with frequent comorbidities, in women, in patients with other malignancies, and those with insulin resistance. LCRCs are diagnosed in particular in people with a low-fibre diet, heavy smokers and in those who consume alcohol. Whereas clinical symptoms of LCRC (change in bowel habits and bleeding) are diagnosed more frequently, and therefore synchronous CLMs are discovered earlier, symptoms of RCRC arise late, with consequently later discovery of synchronous CLMs. Microsatellite instability, high $\mathrm{CpG}$ island methylation (leading to a worse reaction to

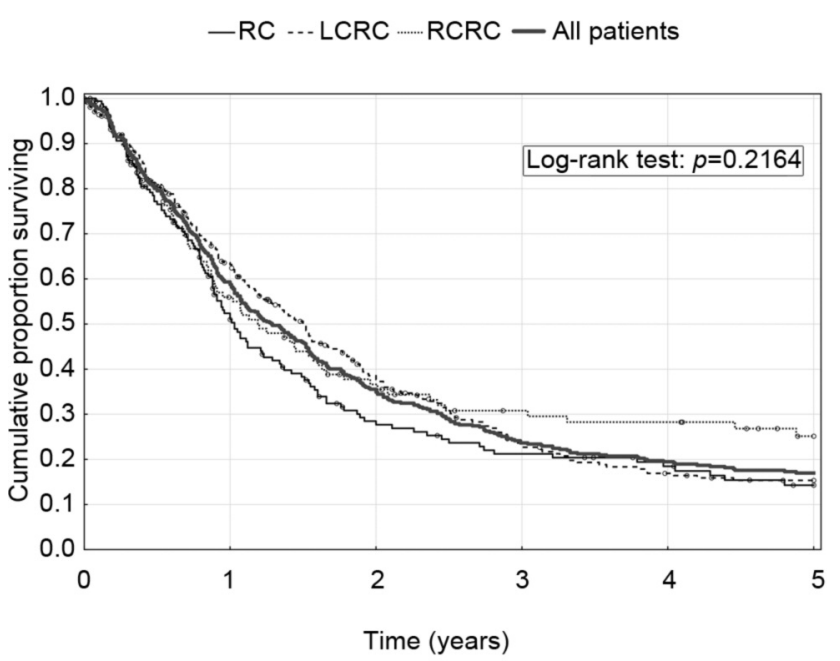

Figure 5. Recurrence-free survival of the entire patient cohort and according to disease. LCRC: Left-sided colorectal cancer; RC: rectal cancer; RCRC: right-sided colorectal cancer. 

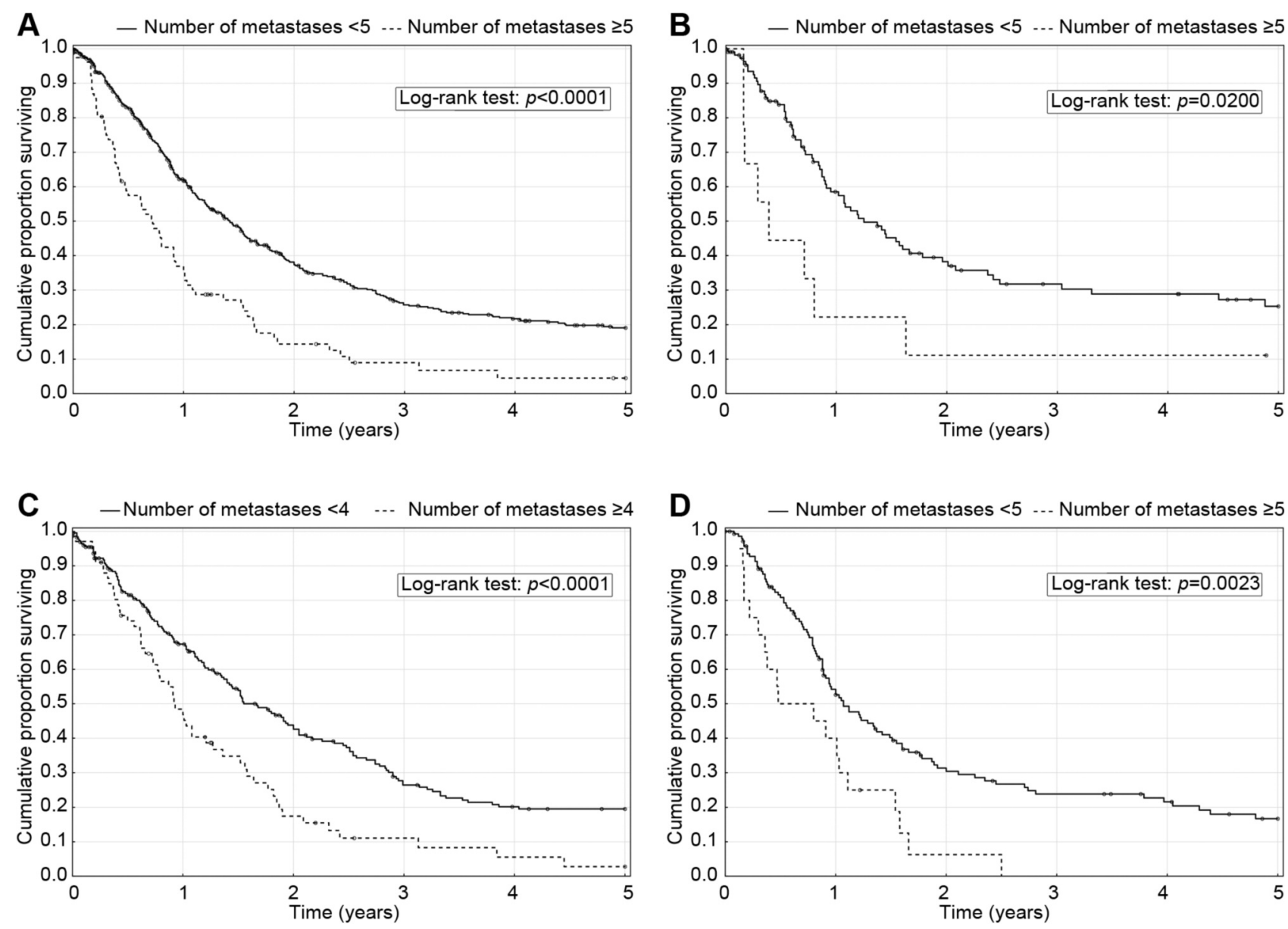

Figure 6. Recurrence-free survival according to the number of colorectal cancer liver metastases for the whole patient cohort (A), for patients with right-sided $(R C R C)(B)$ and left-sided $(L C R C)(C)$ colorectal cancer, and those with rectal cancer $(R C)(D)$.

chemotherapy), and proto-oncogene p2 $1^{\text {ras }}-$ RAS (KRAS codons $12,13,61,146$ and NRAS codons 12,13, 61), protooncogene B-Raf $(B R A F)$ and phosphatidylinositol-3-kinase $(P I 3 K C A)$ mutation are more frequent in RCRC compared with LCRC. These mutations are also associated with more frequent multifocal CLMs. Compared with LCRC, RCRC is more poorly differentiated mucosal type and more frequently metastasizes into the drainage lymphatic nodes and the peritoneum. All of these features are given as the main cause of the greater biological aggression of RCRC and worse OS both for primary resections of colon and for resection of CLMs originating from RCRC (21-24).

Most of the recent studies describe worse long-term OS for patients with CLMs from RCRC (25-28). As regards RFS, the results of studies vary. Some describe worse RFS for LCRC (29), whereas others find no significant difference between RCRC and LCRC $(30,31)$. However, from all the studies it is evident that CLMs from RCRC have a more aggressive biological potential than those from
LCRC. This is also associated with the question of perioperative oncological, in particular neoadjuvant, treatment for these patients. Certain studies in this sense state that a so-called up-front hepatectomy, i.e. hepatectomy without neoadjuvant chemotherapy, in the case of RCRC is associated with significantly worse OS and RFS, whereas the long-term results for hepatectomies performed after neoadjuvant oncological treatment do not differ according to the location of the primary tumour $(32,33)$. In contrast, other studies showed a fundamentally worse response to neoadjuvant chemotherapy and targeted therapy of patients with CLMs from RCRC $(34,35)$. With regard to the longterm results according to tumour location, those with CLMs from RCRC were found to have worse results regardless of the type of operation for CLMs (36).

In contrast with previous studies, in our group of 636 patients, we did not confirm clearly worse long-term OS or RFS for patients following liver procedures for CLMs from RCRC. This may be due to several factors. Firstly, the 

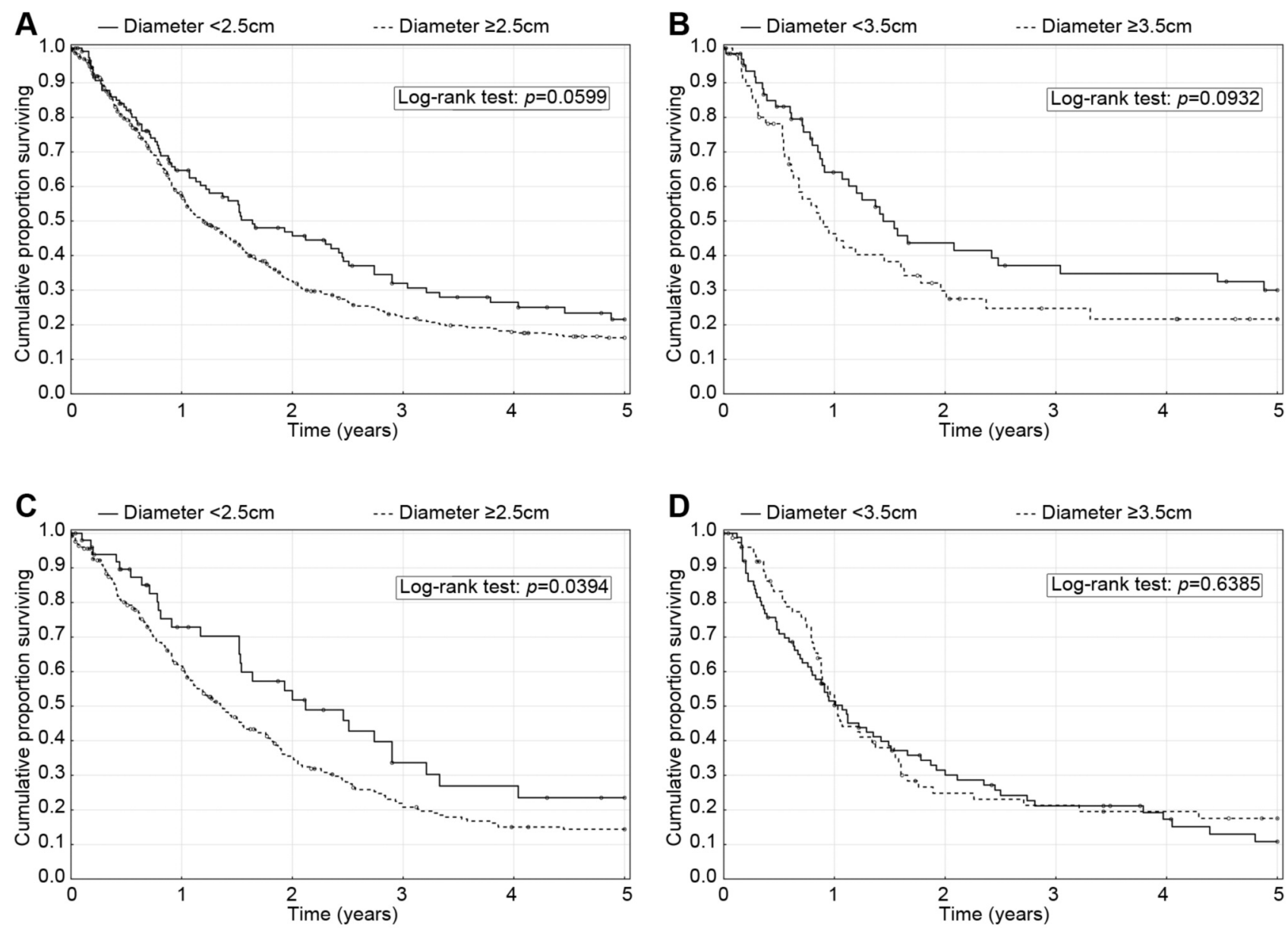

Figure 7. Recurrence-free survival according to the diameter of colorectal cancer liver metastases for the whole patient cohort (A), for patients with right-sided $(R C R C)(B)$ and left-sided $(L C R C)(C)$ colorectal cancer, and those with rectal cancer $(R C)(D)$.

different and non-unified definition of location of RCRC tumours in literature, whose location in the splenic flexure some classify as RCRC, and others as LCRC. The second problem is the non-uniform indication for neoadjuvant oncological treatment in current literature, and in many publications. This treatment is not given in connection with the surgical treatment of CLMs in general. In our group of patients, we did not include neoadjuvant oncological treatment as one of the evaluation criteria due to the fact that we indicate this treatment only for patients with borderline resectability or primary non-resectability of CLMs, regardless of the primary location of tumour. In the case of resectable CLMs, we perform primary resection with subsequent adjuvant oncological treatment. In our study, we also performed an as yet unpublished classification of rectal tumours from the aspect of their metastatic tendency, to the LCRC group in the case of the upper rectum, and to the RC group in the case of the middle and lower rectum. In many other works covering the results of surgical treatment of
CLMs according to primary location of tumour, the location of the tumour in the rectum is not given, or rectal tumours are simply classified as LCRC.

This study was limited by its retrospective nature. It was also a study performed over an interval of 19 years, during which more precise diagnostic and radiological methods as well as surgical techniques developed, primarily mini-invasive methods and methods sparing the liver parenchyma. In addition, there have been changes in the development of effective perioperative oncological treatment over this period. Unfortunately, it was not possible to evaluate this factor in our group of patients mainly due to our current indication for oncological treatment for patients with borderline resectability or primary non-resectability of CLMs. Due to a lack of data about gene mutations, especially for patients from the first years of monitoring, we were unable to adequately evaluate these factors for our group. However, these are currently sufficiently well-known as risk factors for the long-term results of surgical CLM treatment. 

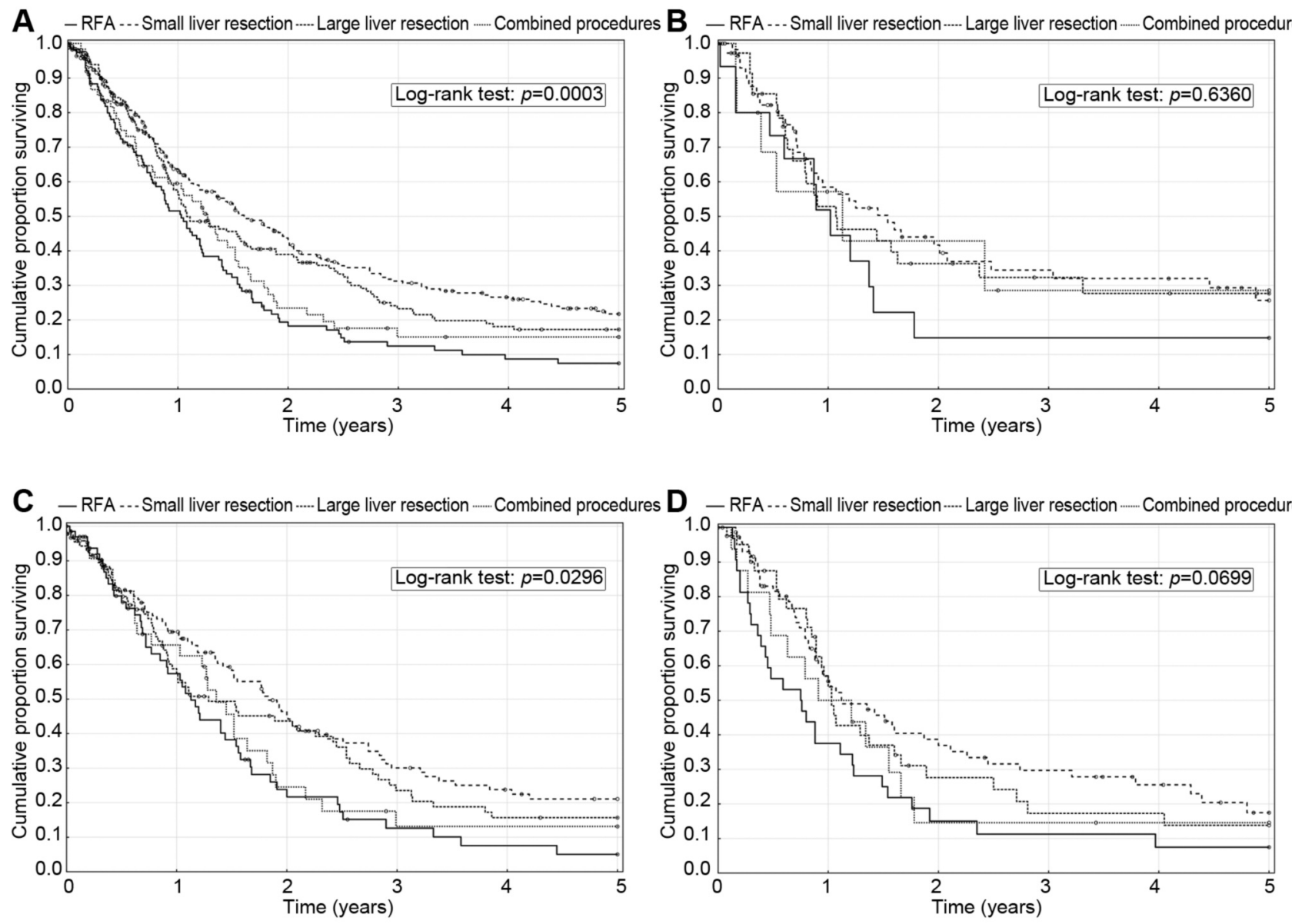

Figure 8. Recurrence-free survival according to the type of surgery for the whole patient cohort (A), for patients with right-sided (RCRC) (B) and left-sided $(L C R C)(C)$ colorectal cancer, and those with rectal cancer $(R C)(D)$. RFA: Radiofrequency ablation.

In conclusion, we assume that the primary tumour location is undoubtedly an important but not fundamental factor influencing the long-term results of surgery for CLMs. Along with the side location of the primary tumour, considering OS and RFS, other clinical risk factors can also be evaluated. It is evident from our results that every patient with CLMs must be evaluated individually by a multidisciplinary team, and the optimal multimodal treatment, the basis of which is liver resection, must be tailored to the patient.

\section{Conflicts of Interest}

No conflicts of interest exist.

\section{Authors' Contributions}

V. Treska: Conception, design, supervision, literature review, writing; Skala: data collection; K. Prochazkova: data collection and processing, analysis; Svejdova: data collection; T. Petrakova: data collection; J. Sebek: data collection; I. Riha: data collection; J. Rosendorf: data collection; R. Polak: data collection; T. Skalicky: critical review; V. Liska: design, critical review.

\section{Acknowledgements}

This study was supported by the Charles University Research Fund (Progres Q39) and by the Ministry of Health of the Czech Republic grant-Conceptual Development of Research Organization (Faculty Hospital in Pilsen - FNPl, 00669806).

\section{References}

1 Rawla P, Sunkara T and Barsouk A: Epidemiology of colorectal cancer: Incidence, mortality, survival and risk factors. Prz Gastroenterol 14(2): 89-103, 2019. PMID: 31616522. DOI: 10.5114/pg.2018.81072

2 Knudsen AB, Zauber AG, Rutter CM, Naber SK, Doria-Rose VP, Pabiniak C, Johanson C, Fischer SE, Lansdorp-Vogelaar I and Kuntz KM: Estimation of benefits, burden and harms of 

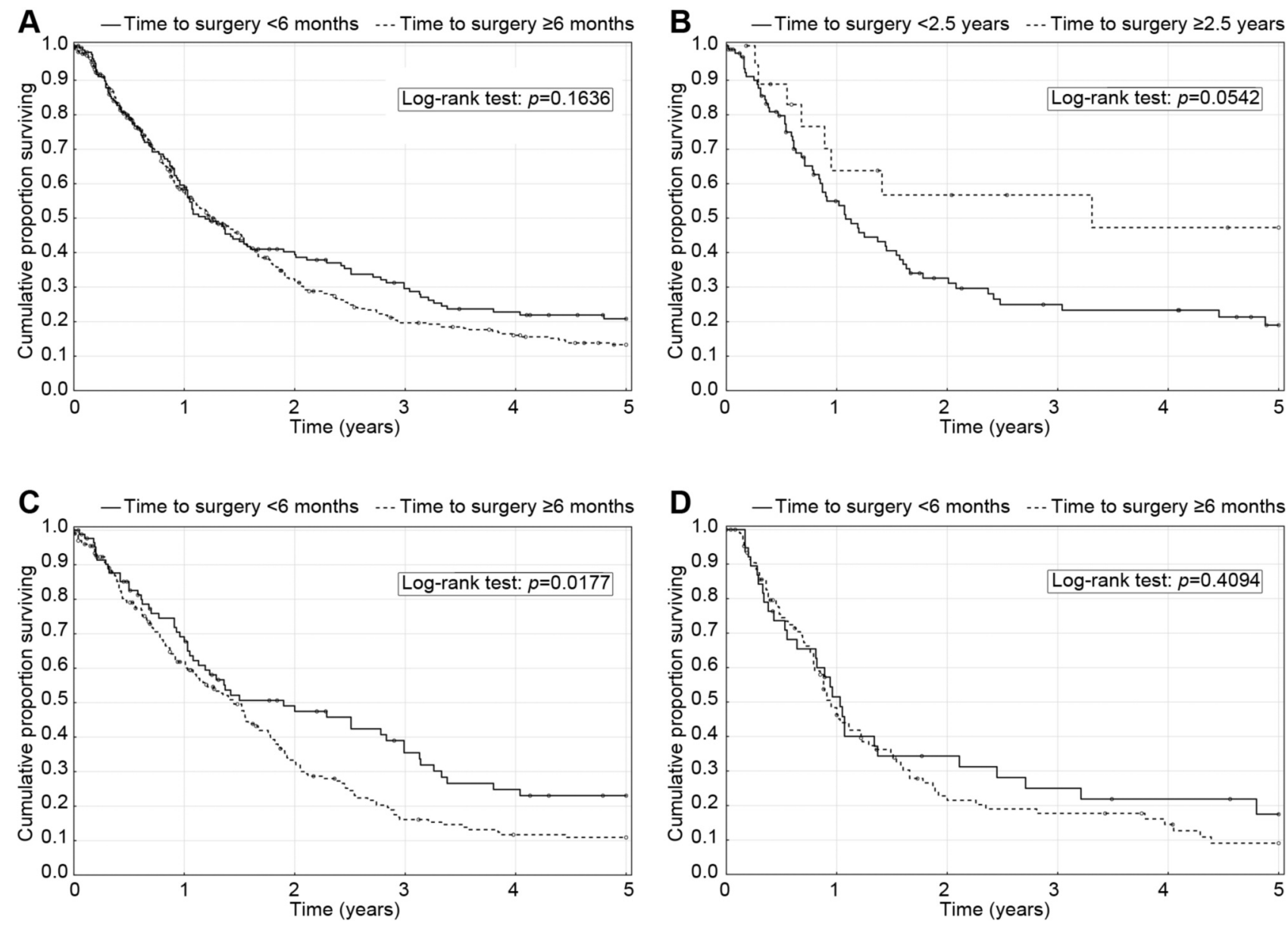

Figure 9. Recurrence-free survival according to the time to surgery of colorectal cancer liver metastases for the whole patient cohort (A), for patients with right-sided $(R C R C)(B)$ and left-sided $(L C R C)(C)$ colorectal cancer, and those with rectal cancer $(R C)(D)$.

colorectal cancer screening strategies: Modeling study for the US Preventive Services Task Force. JAMA 315(23): 2595-2609, 2016. PMID: 27305518. DOI: 10.1001/jama.2016.6828

3 Bruha J, Treska V, Mirka H, Hosek P, Fichtl J, Skalický T, Bajcurova K, Ludvik J, Duras P, Lysak D and Liska V: Growth of colorectal liver metastases is not accelerated by intraportal administration of stem cells after portal vein embolization. Rozhl Chir 98(4): 159-166, 2019. PMID: 31159549.

4 Engstrand J, Nilsson H, Strömberg C, Jonas E and Freedman J: Colorectal cancer liver metastases-a population-based study on incidence, management and survival. BMC Cancer 18(1): 78, 2018. PMID: 29334918. DOI: 10.1186/s12885-017-3925-x

5 Treska V, Bruha J, Skalicky T, Liska V, Fichtl J, Mirka H and Korcakova E: Radiofrequency ablation of colorectal liver metastases. Rozhl Chir 98(10): 399-403, 2019. PMID: 31842569.

6 Öven Ustaalioğlu BB, Tilki M, Kılıçoğlu ZG, Bilici A, Sürmelioğlu A, Ustaalioğlu R and Erkol B: Prognostic markers for metastatic colon cancer patients undergoing multiple metastasectomies. Turk J Gastroenterol 26(5): 386-391, 2015. PMID: 26215062. DOI: 10.5152/tjg.2015.0169
7 Tosi F, Magni E, Amatu A, Mauri G, Bencardino K, Truini M, Veronese S, De Carlis L, Ferrari G, Nichelatti M, SartoreBianchi A and Siena S: Effect of KRAS and BRAF mutations on survival of metastatic colorectal cancer after liver resection: A systematic review and meta-analysis. Clin Colorectal Cancer 16(3): e153-e163, 2017. PMID: 28216246. DOI: 10.1016/j.clcc. 2017.01.004

8 Dupre A, Malik HZ, Jones RP, Diaz-Nieto R, Fenwick SW and Poston GJ: Influence of the primary tumour location in patients undergoing surgery for colorectal liver metastases. Eur J Surg Oncol 44(1): 80-86, 2018. PMID: 29183640. DOI: 10.1016/ j.ejso.2017.10.218

9 Petrelli F, Ghidini M, Barni S, SteCRCanella F, Sgroi G, Passalacqua R and Tomasello G: Prognostic role of primary tumor location in non-metastatic gastric cancer: A systematic review and meta-analysis of 50 studies. Ann Surg Oncol 24(9): 2655-2668, 2017. PMID: 28299508. DOI: 10.1245/s10434-017-5832-4

10 Tomasello G, Petrelli F and Barni S: Risk of primary tumor sidedness as a criterion for screening, diagnostic colonoscopy and surveillance intervals-reply. JAMA Oncol 3(10): 1427, 2017. PMID: 28654989. DOI: 10.1001/jamaoncol.2017.1516 
11 Shen H, Yang J, Huang Q, Jiang MJ, Tan YN, Fu JF, Zhu LZ, Fang XF and Yuan Y: Different treatment strategies and molecular features between right-sided and left-sided colon cancers. World J Gastroenterol 21(21): 6470-6478, 2015. PMID: 26074686. DOI: 10.3748/wjg.v21.i21.6470

12 Liu W, Wang HW, Wang K and Xing BC: The primary tumor location impacts survival outcome of colorectal liver metastases after hepatic resection: A systematic review and meta-analysis. Eur J Surg Oncol 45(8): 1349-1356, 2019. PMID: 31054852. DOI: $10.1016 /$ j.ejso.2019.04.017

13 Ishihara S, Murono K, Sasaki K, Yasuda K, Otani K, Nishikawa T, Tanaka T, Kiyomatsu T, Kawai K, Hata K, Nozawa H, Sugihara $\mathrm{K}$ and Watanabe $\mathrm{T}$ : Impact of primary tumor location on postoperative recurrence and subsequent prognosis in nonmetastatic colon cancers: A multicenter retrospective study using a propensity score analysis. Ann Surg 267(5): 917-921, 2018. PMID: 28272099. DOI: 10.1097/SLA.0000000000002206

14 Pathak S, Palkhi E, Dave R, White A, Pandanaboyana S, Prasad KR, Lodge JP and Toogood GJ: Relationship between primary colorectal tumour and location of colorectal liver metastases. ANZ J Surg 86(5): 408-410, 2016. PMID: 25040656. DOI: 10.1111/ans.12767

15 Yahagi M, Okabayashi K, Hasegawa H, Tsuruta M and Kitagawa Y: The worse prognosis of right-sided compared with left-sided colon cancers: A systematic review and meta-analysis. J Gastrointest Surg 20(3): 648-655, 2016. PMID: 26573851. DOI: 10.1007/s11605-015-3026-6

16 Creasy JM, Sadot E, Koerkamp BG, Chou JF, Gonen M, Kemeny NE, Saltz LB, Balachandran VP, Peter Kingham T, DeMatteo RP, Allen PJ, Jarnagin WR and D'Angelica MI: The impact of primary tumor location on long-term survival in patients undergoing hepatic resection for metastatic colon cancer. Ann Surg Oncol 25(2): 431-438, 2018. PMID: 29181680. DOI: 10.1245/s10434-017-6264-x

17 Price TJ, Beeke C, Ullah S, Padbury R, Maddern G, Roder D, Townsend AR, Moore J, Roy A, Tomita Y and Karapetis C: Does the primary site of colorectal cancer impact outcomes for patients with metastatic disease? Cancer 121(6): 830-835, 2015. PMID: 25377235. DOI: $10.1002 / \mathrm{cncr} .29129$

18 Yamashita S, Odisio BC, Huang SY, Kopetz SE, Ahrar K, Chun YS, Conrad C, Aloia TA, Gupta S, Harmoush S, Hicks ME and Vauthey JN: Embryonic origin of primary colon cancer predicts survival in patients undergoing ablation for colorectal liver metastases. Eur J Surg Oncol 43(6): 1040-1049, 2017. PMID: 28187878. DOI: 10.1016/j.ejso.2017.01.007

19 Katafygiotis P, Sakellariou S, Chatziandreou I, Giannopoulou I, Thymara I, Saetta AA and Korkolopoulou P: Microsatellite instability in Greek colorectal carcinoma patients: Clinicopathological and molecular correlations. Anticancer Res 39(11): 6379-6387, 2019. PMID: 31704871. DOI: 10.21873/ anticanres. 13851

20 Kamocki ZK, Wodyńska NA, Żurawska JL and Zaręba KP: Significance of selected morphological and histopathological parameters of colon tumors as prognostic factors of cancer spread. Turk J Gastroenterol 28(4): 248-253, 2017. PMID: 28699599. DOI: $10.5152 /$ tjg.2017.16734

21 Imai K, Yamashita YI, Miyamoto Y, Nakao Y, Yusa T, Itoyama R, Nakagawa S, Okabe H, Hiyoshi Y, Nitta H, Chikamoto A and Baba H: Implication of primary tumor location for the indication of preoperative chemotherapy in patients with colorectal liver metastases. HPB 21(4): 405-412, 2019. PMID: 30266494. DOI: 10.1016/j.hpb.2018.08.012

22 Liu W, Wang HW, Wang K and Xing BC: The primary tumor location impacts survival outcome of colorectal liver metastases after hepatic resection: A systematic review and meta-analysis. Eur J Surg Oncol 45(8): 1349-1356, 2019. PMID: 31054852. DOI: $10.1016 /$ j.ejso.2019.04.017

23 Gasser E, Braunwarth E, Riedmann M, Cardini B, Fadinger N, Presl J, Klieser E, Ellmerer P, Dupré A, Imai K, Malik H, Baba H, Ulmer H, Schneeberger S, Öfner D, Dinnewitzer A, Stättner $\mathrm{S}$ and Primavesi F: Primary tumour location affects survival after resection of colorectal liver metastases: A two-institutional cohort study with international validation, systematic metaanalysis and a clinical risk score. PLoS One 14(5): e0217411, 2019. PMID: 31150437. DOI: 10.1371/journal.pone.0217411

24 Buisman FE, Galjart B, Buettner S, Groot Koerkamp B, Grünhagen DJ and Verhoef C: Primary tumor location and the prognosis of patients after local treatment of colorectal liver metastases: A systematic review and meta-analysis. HPB, 2019. PMID: 31668753. DOI: 10.1016/j.hpb.2019.10.003

25 Creasy JM, Sadot E, Koerkamp BG, Chou JF, Gonen M, Kemeny NE, Saltz LB, Balachandran VP, Peter Kingham T, DeMatteo RP, Allen PJ, Jarnagin WR and D'Angelica MI: The impact of primary tumor location on long-term survival in patients undergoing hepatic resection for metastatic colon cancer. Ann Surg Oncol 25(2): 431-438, 2018. PMID: 29181680. DOI: 10.1245/s10434-017-6264-x

26 Creasy JM, Sadot E, Koerkamp BG, Chou JF, Gonen M, Kemeny NE, Balachandran VP, Kingham TP, DeMatteo RP, Allen PJ, Blumgart LH, Jarnagin WR and D'Angelica MI: Actual 10-year survival after hepatic resection of colorectal liver metastases: What factors preclude cure? Surgery 163(6): 12381244, 2018. PMID: 29455841. DOI: 10.1016/j.surg.2018.01.004

27 Rajakannu M, Magdeleinat P, Vibert E, Ciacio O, Pittau G, Innominato $\mathrm{P}, \mathrm{SaCunha} \mathrm{A}$, Cherqui $\mathrm{D}$, Morère JF, Castaing $\mathrm{D}$ and Adam R: Is cure possible after sequential resection of hepatic and pulmonary metastases from colorectal cancer? Clin Colorectal Cancer 17(1): 41-49, 2018. PMID: 28709876. DOI: 10.1016/j.clcc.2017.06.006

28 Zarour LR, Anand S, Billingsley KG, Bisson WH, Cercek A, Clarke MF, Coussens LM, Gast CE, Geltzeiler CB, Hansen L, Kelley KA, Lopez CD, Rana SR, Ruhl R, Tsikitis VL, VaCRCaro GM, Wong MH and Mayo SC: Colorectal cancer liver metastasis: Evolving paradigms and future directions. Cell Mol Gastroenterol Hepatol 3(2): 163-173, 2017. PMID: 28275683. DOI: $10.1016 /$ j.jcmgh.2017.01.006

29 Palkovics A, Vereczkei A, Fincsur A, Kiss I, Németh B, Takács I and Papp A: Short- and long-term histological changes in liver parenchyma after different resection methods and their potential role in treatment of colorectal liver metastasis. Anticancer Res 40(3): 1359-1365, 2020. PMID: 32132032. DOI: 10.21873/ anticanres. 14077

30 Lee GH, Malietzis G, Askari A, Bernardo D, Al-Hassi HO and Clark SK: Is right-sided colon cancer different to left-sided colorectal cancer? A systematic review. Eur J Surg Oncol 41(3): 300-308, 2015. PMID: 25468456. DOI: 10.1016/j.ejso.2014.11.001

31 Warschkow R, Sulz MC, Marti L, Tarantino I, Schmied BM, Cerny $\mathrm{T}$ and Güller $\mathrm{U}$ : Better survival in right-sided versus leftsided stage I-III colon cancer patients. BMC Cancer 16: 554, 2016. PMID: 27464835. DOI: 10.1186/s12885-016-2412-0 
32 Lee L, Erkan A, Alhassan N, Kelly JJ, Nassif GJ, Albert MR and Monson J: Lower survival after right-sided versus left-sided colon cancers: Is an extended lymphadenectomy the answer? Surg Oncol 27(3): 449-455, 2018. PMID: 30217301. DOI: $10.1016 /$ j.suronc.2018.05.031

$33 \mathrm{Ke} \mathrm{S}$, Zhan S, Zhu H and Yan D: Topics related to neoadjuvant chemotherapy for resectable liver metastases from colorectal cancer. J BUON 23(2): 296-301, 2018. PMID: 29745068.

34 Ichida $\mathrm{H}$, Mise $\mathrm{Y}$, Ito $\mathrm{H}$, Ishizawa $\mathrm{T}$, Inoue $\mathrm{Y}$, Takahashi $\mathrm{Y}$, Shinozaki E, Yamaguchi K and Saiura A: Optimal indication criteria for neoadjuvant chemotherapy in patients with resectable colorectal liver metastases. World J Surg Oncol 17(1): 100, 2019. PMID: 31196104. DOI: 10.1186/s12957-019-1641-5

35 Yamashita S, Brudvik KW, Kopetz SE, Maru D, Clarke CN, Passot G, Conrad C, Chun YS, Aloia TA and Vauthey JN: Embryonic origin of primary colon cancer predicts pathologic response and survival in patients undergoing resection for colon cancer liver metastases. Ann Surg 267(3): 514-520, 2018. PMID: 28002060. DOI: 10.1097/SLA.0000000000002087

36 Sasaki K, Andreatos N, Margonis GA, He J, Weiss M, Johnston F, Wolfgang C, Antoniou E, Pikoulis E and Pawlik TM: The prognostic implications of primary colorectal tumor location on recurrence and overall survival in patients undergoing resection for colorectal liver metastasis. J Surg Oncol 114(7): 803-809, 2016. PMID: 27792291. DOI: $10.1002 /$ jso. 24425

Received April 11, 2020

Revised April 28, 2020

Accepted May 5, 2020 